\title{
The Effect of Bisphenol A Polyether Polyols on the Synthesis of Hydrophilic Epoxy Resins
}

\author{
${ }^{1 *}$ Jinhua Yi and ${ }^{2}$ Xin Yuan \\ ${ }^{1}$ Institute of Road and Bridge Engineering, Hunan Communication Polytechnic, Changsha 410132, China \\ ${ }^{2}$ Hunan Expressway Group Co., Ltd, Changsha 410003, China
}

Article history

Received: 26-03-2021

Revisad: $15-06-2021$

Aceptad: 23-06-2021

Corresponding Author:

Jinhua Yi

Institute of Road and Bridge

Engineering, Hunan

Communication Polytechnic,

Changsha 410132, China

Email: 54062584@qq.com

\begin{abstract}
The article uses three types of Bisphenol A polyether polyols BEO, BPO-6 and BPO-10 as raw materials, reacts with epichlorohydrin under the action of a catalyst and synthesizes a hydrophilic epoxy resin. The molecular structure of the product is analyzed by infrared spectroscopy and the results show that the synthesis of the hydrophilic epoxy resin BEOGE conforms to the results of the experimental design. The research results show that the hydrophilicity, epoxy value, tensile strength and elongation rate of cured product of BEOGE synthesized from BEO are better than those synthesized by BPO-6 and BPO-10 and the hydrophilic-lipophilic balance value of BEOGE is 6.531, which is between epoxy resin and water-based epoxy resin. It facilitates its adsorption at the oil-water interface and meets the synthesis requirements of hydrophilic epoxy resin. When tetra ethylene pen amine is used as the curing agent, the tensile strength and elongation at break of the cured product are tested. The results show that the tensile strength and elongation at break of the cured product of BEOGE are far better than those of BPOGE-6 and BPOGE-10. Among them, the BEOGE cured product has the highest tensile strength value of $0.59 \mathrm{MPa}$, which is 1.79 times that of BPOGE-6 and 4.92 times that of BPOGE-10. The elongation at break of the cured product of BEOGE is the largest at $9.9 \%$, which is 1.87 times of that of BPOGE- 6 and 1.46 times of that of BPOGE- 10 .
\end{abstract}

Keywords: Hydrophilic Epoxy Resin, Bisphenol Polyether Polyol, Epichlorohydrin, Synthesis

\section{Introduction}

Epoxy Resin generally refers to two or more reactive epoxy groups. The molecular skeleton is aliphatic, alicyclic or aromatic organic compounds and the thermosetting product is formed by the reaction of reactive epoxy group and curing agent, which is a polymer oligomer. Epoxy resin has been widely used in architecture (Huseien et al., 2021; Yu et al, 2021; Papanicolaou and Anastasiou, 2021), coatings (Wang et al., 2021; Li et al., 2021; Fernández-Álvarez et al., 2021), electronics (Kong et al., 2019; Jdidi et al., 2021; Lee et al., 2021), medical treatment (Kumar and Swamy, 2021) and packaging (Parvathy and Sahoo, 2021), due to its advantages of high hardness, insulation, anti-corrosion and high adhesion. There are many types of epoxy resins. At present, many researchers at home and abroad are committed to preparing environmentally friendly bio-based epoxy resins using natural products as initial raw materials (Faye et al., 2017; Janvier et al., 2017;
Essid et al., 2021). The output of Bisphenol A epoxy resins is the largest (accounting for about $90 \%$ of total epoxy resin output in China and $75-80 \%$ of the world) and it is the most widely used. There are many types of epoxy resins. Among them, Bisphenol A epoxy resin has the largest output (accounting for about $90 \%$ of total epoxy resin output in China and $75-80 \%$ of the world). Bisphenol A epoxy resin, i.e., diphenol propane glycidyl ether, is formed by polycondensation of Bisphenol A and epichlorohydrin under the action of a basic catalyst (Janvier et al., 2017).

Since most epoxy resins are not hydrophilic and cannot be dissolved in water (Guo et al., 2017), but can only be dissolved in organic solvents, such as aromatic hydrocarbons and ketones. Thus, they will cause excessive strength loss during construction on wet surfaces. Organic solvents are flammable, explosive, toxic, polluting the environment and more. As an environmentally friendly material that does not contain VOC, contains low VOC or does not contain HAP, waterborne epoxy resin has excellent bonding 
properties and can be constructed on wet surfaces. It has low requirements for environment, is easy to clean, convenient for storage and transportation, safe to use, thus it is more and more valued and applied by people. However, because water-based epoxy resin uses water as a solvent, it has the disadvantages of slow curing, low strength, large shrinkage, poor freeze-thaw stability and poor corrosion resistance and is not suitable for application in structural reinforcement.

Polyether polyol is an important chemical raw material and its main application is as a raw material for synthetic polyurethane resin products. There are two main synthesis methods for Bisphenol A polyether polyol according to different raw materials: One is based on Bisphenol A as the initiator and ethylene oxide or chloroethanol or ethylene carbonate is a hydroxyethylation reagent that synthesizes Bisphenol A polyether polyol under alkali catalysis (Berti et al., 2004) the other is synthesized from Bisphenol A polycarbonate through chemical recycling. In addition, studied the reaction of Bisphenol $\mathrm{A}$ and epichlorohydrin under an alkaline catalyst to produce Bisphenol A diglycidyl ether (Munguia-Lopez and Soto-Valdez, 2001) and then (Bogdal et al. 2016) used microwave radiation to synthesize Bisphenol A diglycidyl ether (Dariuszet al., 2016). The molecular structure of Bisphenol A polyether polyol (formed by introducing ether bonds with certain hydrophilicity and flexibility into the rigid Bisphenol A skeleton) contains multiple ether bonds (-R-O-R-) with hydroxyl groups (-OH) at both ends. Both ether bonds and hydroxyl groups are strong hydrophilic groups, which will increase its hydrophilicity.

In this study, Bisphenol A polyether polyol is used as a synthetic raw material to epoxidize with epichlorohydrin to synthesize an epoxy resin with amphiphilic functionality. Make it both lipophilic and hydrophilic, improve the overall performance of the current epoxy resin system and especially improve the bonding performance of the epoxy resin during construction on the wet surface. The epoxy resin synthesized by this method is named hydrophilic epoxy resin.

\section{Experiment}

\section{Laboratory Reagents and Instruments}

\section{Selection of Bisphenol A Polyether Polyol}

Bisphenol A polyether polyol is an aromatic polymer with multiple ether bonds (-R-O-R-) in the molecular structure and hydroxyl groups $(-\mathrm{OH})$ at both ends. In this study, three types of Bisphenol A polyether polyols, BEO-6, BPO-6 and BPO-10 are selected for experiments and their properties are shown in Table 1. Among them, the molecular structures of BEO-6, BPO-6 and BPO-10 (Fig. 1 for the molecular structure) are similar and belong to the same series of Bisphenol A polyether polyols, all of which are made of Bisphenol A as raw materials and ethylene oxide. Alkane or propylene oxide is a hydroxyethylation reagent, synthesized by a ringopening polymerization reaction under base catalysis. Among them, BEO- 6 and BPO- 6 both contain 6 ether bonds and BPO-10 contains 10 ether bonds.

\section{Other Main Experimental Reagents}

Epichlorohydrin, industrial grade, from Lianyungang Huanhai Chemical Co., Ltd.; Toluene, analytically pure, from Jiangsu Qiangsheng Chemical Co., Ltd; Acetone, analytically pure from Jiangsu Qiangsheng Chemical Co., Ltd; Sodium hydroxide, analytical reagent from Jiangsu Qiangsheng Chemical Co., Ltd. The curing agent is Tetraethylene Pentamine (TEPA) from Changshu Jiafa Chemical Co., Ltd.

\section{Experimental Instruments}

CS501 super constant temperature water bath from Shanghai Jinping Instrument Co., Ltd.; JJ-1 type precision power-increasing electric stirrer from Jintan Kexi Instrument Co., Ltd.; NDJ-5S digital viscometer from Shanghai Nirun Intelligent Technology Co., Ltd.; HY-5 type cyclotron oscillator from Changzhou Boyuan Experimental Analytical Instrument Factory; DZ-1 potentiometric titration device from Shanghai Dapu Instrument Co., Ltd.; F0.4 high-speed dispersing machine (0-8000 $\mathrm{r} / \mathrm{min})$ from Jiangyin Jingyi Chemical Machinery; Model 101-1 electric heating blast drying oven $\left(10-250^{\circ} \mathrm{C}\right)$ from Shanghai Shili Instrument Co., Ltd.; WQF-410 Fourier Transform Infrared Spectrometer from Beijing Ruili Analytical Instrument Co., Ltd.; and the temperature regulating electric heater from Tongzhou Shentong Electric Heater Factory and more.

\section{Experimental Operation}

$0.5 \mathrm{~mol}$ different types of a polyether polyols and 200$250 \mathrm{~g}$ of toluene were put into a $1 \mathrm{~L}$ four-necked flask with a thermometer, a reflux condenser, a dropping funnel and mechanical stirring. Meanwhile, the catalyst was added for stirring and the temperature was raised to $60-70^{\circ} \mathrm{C}$ to make the raw materials completely dissolved. Keep a certain temperature, slowly add epichlorohydrindropwise, control the dropping time of epichlorohydrin and observe the reaction exotherm at the same time, let it cool down after maintaining. Then add 200-250 $\mathrm{g}$ of toluene and add $\mathrm{NaOH}$ at a certain temperature and maintain it for a certain time. Finally, $100 \mathrm{~g}$ of toluene is added, neutralized, filtered; toluene is removed under reduced pressure and the material is discharged by cooling down and filtering. 
Table 1: Types and properties of a polyether polyol

\begin{tabular}{llllll}
\hline Species & $\begin{array}{l}\text { Relative molecular } \\
\text { mass }(\mathrm{g} / \mathrm{mol})\end{array}$ & $\begin{array}{l}\text { Viscosity } \\
\left(\mathrm{mPa} \cdot \mathrm{s}, 25^{\circ} \mathrm{C}\right)\end{array}$ & HLB value & Property & Manufacturer \\
\hline BEO-6 & 492 & 3389.0 & 8.031 & Colorless to yellowish transparent liquid & Aoki Oil Industry Co., Ltd. \\
BPO-6 & 576 & 4302.3 & 5.151 & Colorless transparent liquid & \\
BPO-10 & 808 & 1346.4 & 4.551 & Colorless transparent liquid & \\
\hline
\end{tabular}
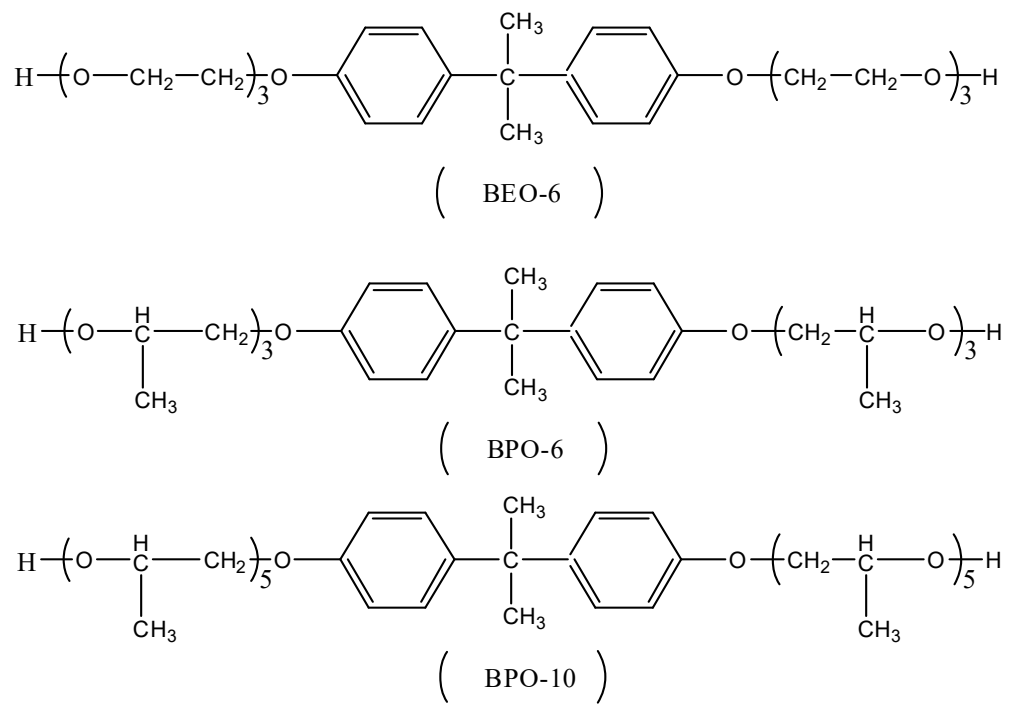

Fig. 1: Molecular structure of a polyether polyol BEO-6, BPO-6 and BPO-10

Table 2: The number of HLB groups of commonly used surfactants

\begin{tabular}{|c|c|c|c|}
\hline \multicolumn{2}{|l|}{$\begin{array}{l}\text { Number of } \\
\text { hydrophilic groups }\end{array}$} & \multicolumn{2}{|l|}{$\begin{array}{l}\text { Number of } \\
\text { lipophilic groups }\end{array}$} \\
\hline$-\mathrm{SO}_{4} \mathrm{Na}$ & 38.7 & $-\mathrm{CH}-$ & -0.475 \\
\hline -COOK & 21.1 & $-\mathrm{CH}_{2}-$ & -0.475 \\
\hline$-\mathrm{COONa}$ & 19.1 & $-\mathrm{CH}_{3}$ & -0.475 \\
\hline -N(Tertiary amine) & 9.4 & $=\mathrm{CH}-$ & -0.475 \\
\hline Ester (Sorbitan ring) & 6.8 & $-\mathrm{CF}_{2-}$ & -0.870 \\
\hline Ester (free) & 2.4 & $-\mathrm{CF}_{3}$ & -0.870 \\
\hline$-\mathrm{COOH}$ & 2.1 & Benzene ring & -1.662 \\
\hline$-\mathrm{OH}$ & 1.9 & $-\mathrm{CH}_{2}-\mathrm{CH}_{2}-\mathrm{CH}_{2}-\mathrm{O}-$ & -0.15 \\
\hline$-\mathrm{O}-$ & 1.3 & $-\mathrm{CH}\left(\mathrm{H}_{3}\right) \mathrm{CH}_{2}-\mathrm{O}-$ & -0.15 \\
\hline -OH(Sorbitan) & 0.5 & $-\mathrm{CH}_{2} \mathrm{CH}\left(\mathrm{CH}_{3}\right)-\mathrm{O}-$ & -0.15 \\
\hline$-\mathrm{CH}_{2}-\mathrm{CH}_{2}-\mathrm{O}-$ & 0.33 & & \\
\hline
\end{tabular}

\section{Characterization and Testing Determination of} Epoxy Value

In this study, the epoxy value is used to express the content of epoxy groups in the epoxy resin, which is determined by the hydrochloric acid acetone method. Accurately weigh $0.5000-1.5000 \mathrm{~g}$ epoxy resin, place it in a $150 \mathrm{~mL}$ Erlenmeyer flask, add $20.0 \mathrm{~mL} \mathrm{HCl}$-acetone solution (concentrated $\mathrm{HCl} 1 \mathrm{~mL}$, dissolved in $40 \mathrm{~mL}$ acetone, ready-to-use), stopper the bottle and shake well, so that the sample is completely dissolved. Place the sample in a cool place for $1 \mathrm{~h}$, add 2 to 3 drops of methyl red indicator and then titrate with a $0.1 \mathrm{~mol} / \mathrm{L} \mathrm{NaOH}$ standard solution. The color of the solution changes from red to yellow as the end point. Meanwhile, a blank test is carried out.
The epoxy value is calculated according to Eq. (1):

$$
E=\frac{\left(V_{0}-V_{1}\right) \times N_{\mathrm{NaOH}}}{10 W}
$$

where, E-Epoxy value $(\mathrm{mol} / 100 \mathrm{~g}) ; V_{0}$ - volume of $\mathrm{NaOH}$ solution consumed by blank $(\mathrm{mL}) ; V_{1}$ - the volume of $\mathrm{NaOH}$ solution consumed by the sample(ml); $W$ the quality of epoxy $\operatorname{resin}(\mathrm{g}) ; \mathrm{N}_{\mathrm{NaOH}^{-}}$ Concentration of $\mathrm{NaOH}$ solution $(\mathrm{mol} / \mathrm{L})$.

\section{Determination of Viscosity}

According to the Appendix k of GB/T 50550-2016 "Code for Acceptance of Construction Quality of Strengthening Building Structures", NDJ-5S rotary viscometer is used.

\section{Determination of Organochlorine}

The determination of the organic chlorine content of epoxy resin is carried out referring to the test method in GB/T 4618.1-2008 "Plastics-Epoxy ResinsDetermination of chlorine content".

\section{Determination of Inorganic Chlorine}

Light-colored epoxy resin can refer to the alkali ethanol method in HG 2-741-72; For dark epoxy resin, refer to the potentiometric titration method in $\mathrm{GB} / \mathrm{T}$ 4618.1-2008 "Plastics-Epoxy Resins-Determination of chlorine content". 


\section{Exterior}

The color and transparency of the hydrophilic epoxy resin were determined by visual inspection.

\section{Calculation of $H L B$}

The HLB value (i.e., the hydrophilic-lipophilic balance value) refers to the relative ratio of the hydrophilic part to the lipophilic capacity of the surfactant molecule structure. It reflects the group size and power balance of the opposite lipophilic and the hydrophilic in the surfactant molecule, which is a quantitative measure of the relative size of the amphiphilic nature of surfactants. The HLB value of lipophilic surfactants is low and that of hydrophilic surfactants is high. The strong lipophilicity or hydrophilicity of surfactants is not conducive to their effective adsorption on the oil-water interface. J. T. Davies treated HLB value as the synthesis of structure factors and decomposed the structure of surfactant into some groups; each group had a certain contribution to HLB value. The HLB value of various groups can be obtained from the experiment and this value is called the HLB value of the number of groups. Substituting the number of HLB value groups into Eq. (2), the HLB value of the surfactant can be calculated:

HLB value $=\sum$ (Number of Hydrophilic Genes $)$

$+\sum$ (Number of lipophilic genes $)+7$

The number of HLB groups of commonly used surfactants is shown in Table 2.

\section{Observation of Water Dispersibility}

The water dispersibility is observed visually and the results can be expressed in four levels: level 1, level 2, level 3 and level 4. Among them, level 1 means that the synthesized product is uniformly dispersed in water; the solution is colorless or milky white and there is no granular synthesized product. Level 2 means that the synthesis product is uniformly dispersed in water; the solution is white and there is no granular synthesis product. Level 3 means that the synthesized product is more uniformly dispersed in water and a small amount of synthesized product can be seen in the form of particles on the bottle wall. Level 4 means that the synthesis product is not uniformly dispersed in water and a large amount of synthesis product exists in the form of granules.

\section{Infrared Spectrum Test}

The WQF-410 Fourier Transform Infrared Spectrometer is used to conduct an infrared test on the synthesized product-the hydrophilic epoxy resin BEOGE at room temperature.

\section{Results and Discussion}

The Effect of Different Type of a Polyether Polyol on the Physical and Chemical Properties of the Synthesized Product

The final products synthesized by a Polyether polyols BEO-6, BPO-6 and BPO-10 are BEOGE, BPOGE-6 and BPOGE-10 respectively, as shown in Fig. 2.

Some physical and chemical properties of the final synthesized hydrophilic epoxy resin are shown in Table 3.

According to Table 3, the HLB values of BEO-6, BPO-6 and BPO-10 synthesized by BEOGE, BPOGE-6 and BPOGE-10 decrease in turn. The water dispersibility is closely related to the HLB value of the product. The greater the HLB value of the product, the better its water dispersibility, that is, the better its hydrophilicity. The reason for this phenomenon is related to the types of a polyether polyol. The greater the HLB value of a polyether polyol, the greater the HLB value of the synthesized product. Generally, the HLB value of ordinary epoxy resin is less than 3 , while that of waterbased epoxy resin is in 8-18. Too strong lipophilicity or hydrophilicity is not conducive to its effective absorption in oil-water. On the interface, the HLB value of BEOGE is 6.531 , which is conducive to its adsorption on the oilwater interface.

\section{The Effect of Different Types of a Polyether Polyol on the Epoxy Value of Synthetic Product}

The effect of different types of a polyether polyol on the epoxy value of the synthesized product is shown in Fig. 3. It can be seen from Fig. 3 that the epoxy values of BEOGE, BPOGE- 6 and BPOGE-10 decrease from left to right. This phenomenon is related to the relative molecular mass of the product and the mass fraction of epoxy groups. The theoretical epoxy value of epoxy resin, $E_{\text {Theorem }}=\frac{100 \times \text { Mass fraction of epoxy groups }}{43}$ and the molecular structures of BEOGE, BPOGE-6 and BPOGE10 all contain two epoxy groups. Thus, the formula for calculating the theoretical value of epoxy value can be converted

into:

$$
E_{\text {Theorem }}=\frac{100 \times 2}{\text { Relative molecular weight of product }} \text { It can be seen }
$$

that the higher the relative molecular weight of the product, the lower the epoxy value. The relative molecular masses of BEOGE, BPOGE-10 and BPOGE6 are 604,688 and $920 \mathrm{~g} / \mathrm{mol}$ respectively. Therefore, their theoretical values will decrease sequentially, which is consistent with the experimental results.

Epoxy value is the most important functional group in the molecular structure of epoxy resin. Its size is directly 
related to the crosslinking density of cured products and determines the quality of cured products. Therefore, the higher the epoxy value is, the higher the strength of cured products is. It can be seen from Fig. 3 that the cured strength of BEOGE is the highest in BEOGE, BPOGE-6 and BPOGE-10.

\section{The Effect of Different Types of a Polyether Polyol on the Viscosity of Synthetic Product}

From Fig. 4, the viscosity of BEOGE, BPOGE-6 and BPOGE-10 is in the order of BPOGE-6, BEOGE and BPOGE-10. Among them, the viscosity of BPOGE-6 is 1.24 times that of BEOGE and 1.85 times that of BPOGE-10. The results show that the polyols of a polyether are BEO-6, BPO-6 and BPO-10 and the viscosities of these three raw materials are $3389.0 \mathrm{mPa} \cdot \mathrm{s}, 4302.3$ and $1346.4 \mathrm{mPa} \cdot \mathrm{s}$. The viscosity of BPO- 6 is 1.27 times of that of BEO- 6 and 3.20 times of that of BPO-10 respectively, which is consistent with that of the product. The reason for the viscosity change is mainly related to its own average relative molecular mass and the distribution of relative molecular mass (i.e., dispersity). The viscosity increases with the increase of the average relative molecular mass and decreases with the decrease of the relative molecular mass distribution.

The Effect of Different Types of a Polyether Polyol on the Tensile Properties of Hydrophilic Epoxy Resin

BEOGE, BPOGE-6 and BPOGE-10 were cured under certain conditions with Tetraethylenepentamine (TEPA). The tensile strength and elongation at break of the cured product were measured respectively to compare the tensile strength of these three products. The addition amount of curing agent and curing conditions are shown in Table 4.

Figure 5 shows the effect of different types of a polyether polyol on the tensile properties of the cured product. It can be seen from Fig. 5 that when TEPA is used as the curing agent, the tensile strength of BEOGE, BPOGE-6 and BPOGE-10 decreases from left to right. Among them, the BEOGE has the highest tensile strength of $0.59 \mathrm{MPa}$, which is 1.79 times that of the BPOGE-6 cured product and 4.92 times that of the BPOGE-10 cured product. The main reason that affects the tensile strength of cured products of BEOGE, BPOGE-6 and BPOGE-10 is the size of the epoxy value. The larger the epoxy value, the greater the crosslinking density of the cured product and the higher the tensile strength. However, the tensile strength of the cured products of these three synthetic products is low, which is far lower than the technical requirements for structural reinforcement adhesives in the "Code for Design of Reinforcement of Concrete Structures” (GB 50367-2013).

It can be seen from Fig. 5 that when TEPA is used as curing agent, the elongation at break of the cured products of BEOGE, BPOGE- 6 and BPOGE-10 is in the order of BEOGE, BPOGE-10 and BPOGE-6. Among them, the fracture elongation of BEOGE is the largest with $9.9 \%$, which is 1.87 times of that of BPOGE- 6 and 1.46 times of that of BPOGE-10 respectively. The main reason that affects the elongation at break of BEOGE, BPOGE-6 and BPOGE-10 is the mass fraction of the flexible segment (ether bond) in the molecular structure of the synthesized product. In the three products of BEOGE, BPOGE-6 and BPOGE-10, the mass fractions of ether bonds in the molecular structure of the product are 21.2, 18.6 and $20.9 \%$ respectively, which is consistent with the change of elongation at break of the cured products. The "Code for Design of Reinforcement of Concrete Structures" (GB 50367-2013) requires that the elongation at break of the adhesive for structural reinforcement is $\geq 1.5 \%$. While the elongation at break of BEOGE, BPOGE-6 and BPOGE-10 are all higher than the requirements for adhesives in the specification. Therefore, the toughness of these three synthetic products is better.

By comparing the tensile strength and elongation at break of the cured products of BEOGE, BPOGE- 6 and BPOGE-10, it can be seen that the tensile strength and elongation at break of the synthetic product BEOGE are higher than those of the other two products. Therefore, the tensile properties of BEOGE are better than the two synthetic products of BPOGE-6 and BPOGE-10.

\section{Synthesis Principle Analysis}

Using a polyether polyol BEO-6 as a raw material, it undergoes etherification with Epichlorohydrin (ECH) under the action of a catalyst to form chlorohydrin ether to increase the hydrophilicity of the product and then reacts with Sodium Hydroxide $(\mathrm{NaOH})$ to form a ringclosure reaction to form affinity Waterborne epoxy resin BEOGE. The reaction process of synthesizing hydrophilic epoxy resin BEOGE is shown in Fig. 6 and 7:

(1) Etherification reaction-using a polyether polyol to react with epichlorohydrin to form chlorohydrin ether and the reaction process is shown in Fig. 7

(2) Ring-Closure Reaction-Then it reacts with Sodium Hydroxide $(\mathrm{NaOH})$ and dehydrochlorides to synthesize hydrophilic epoxy resin. The reaction formula is shown in Fig. 8 
Jinhua Yi and XinYuan / American Journal of Biochemistry and Biotechnology 2021, 17 (3): 302.311

DOI: 10.3844/ajbbsp.2021.302.311

Table 3: Physical and chemical properties of the final synthesized hydrophilic epoxy resin

Types of

\begin{tabular}{lllll} 
A polyether polyol & Synthetic product & Experimental phenomenon & HLB value & Water dispersibility \\
\hline BEO-6 & BEOGE & Red-brown transparent liquid & 6.531 & Level 2 \\
BPO-6 & BPOGE-6 & Colorless transparent liquid & 3.651 & Level 4 \\
BPO-10 & BPOGE-10 & Light yellow to light pink transparent liquid & 3.051 & Level 4 \\
\hline
\end{tabular}

Table 4: The curing conditions and curing agent content of BEOGE, BPOGE-6 and BPOGE-10

\begin{tabular}{llll}
\hline No. & Synthetic product & curing conditions & TEPA yield (\%) \\
\hline 1 & BEOGE & $30 \sim 40^{\circ} \mathrm{C} 4 \mathrm{~h}+80^{\circ} 6 \mathrm{~h}$ & 7.5 \\
2 & BPOGE-6 & & 5.6 \\
3 & BPOGE-10 & 4.6 & \\
\hline
\end{tabular}

Note: The content of curing agent is calculated according to the formula: Curing agent content $=$ epoxy value of epoxy resin $\times$ active hydrogen equivalent of curing agent and the content of TEPA is calculated based on the mass percentage of the synthetic product

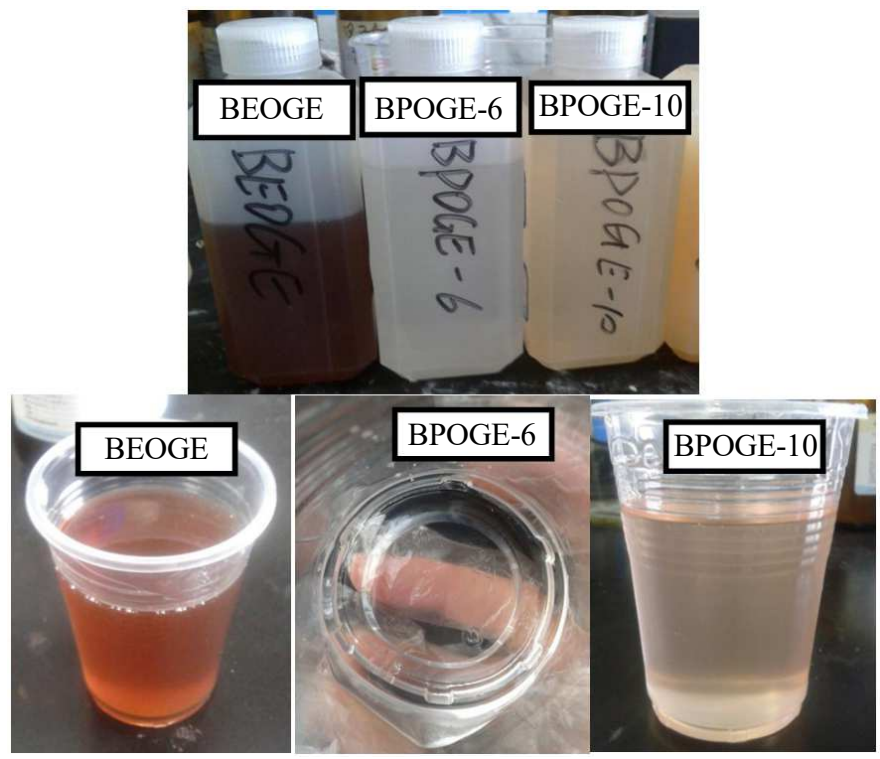

Fig. 2: Synthetic product

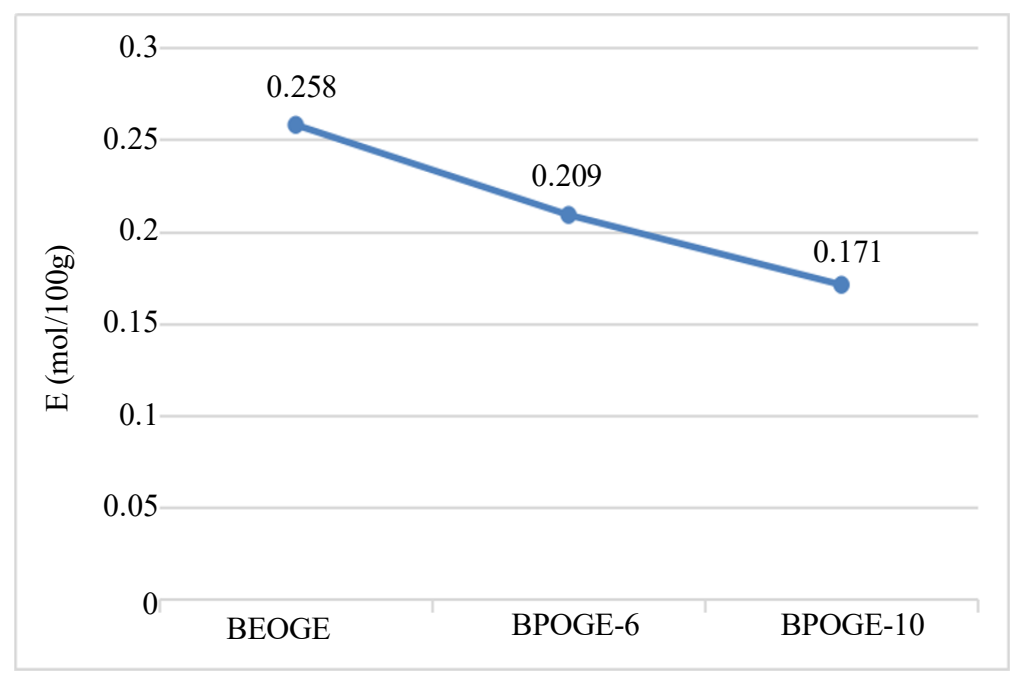

Fig. 3: The influence of different types of a polyether polyol on the epoxy value of synthetic product 


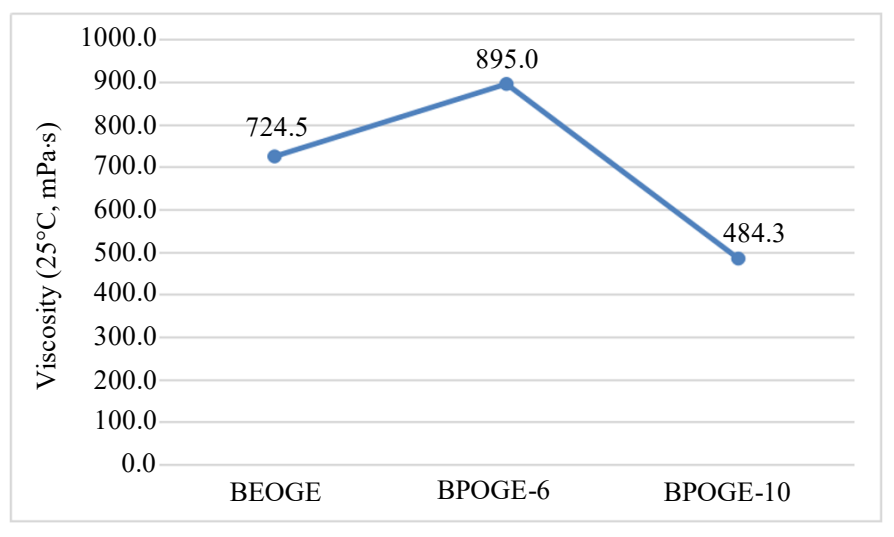

Fig. 4: The effect of different types of a polyether polyol on the viscosity of synthetic product

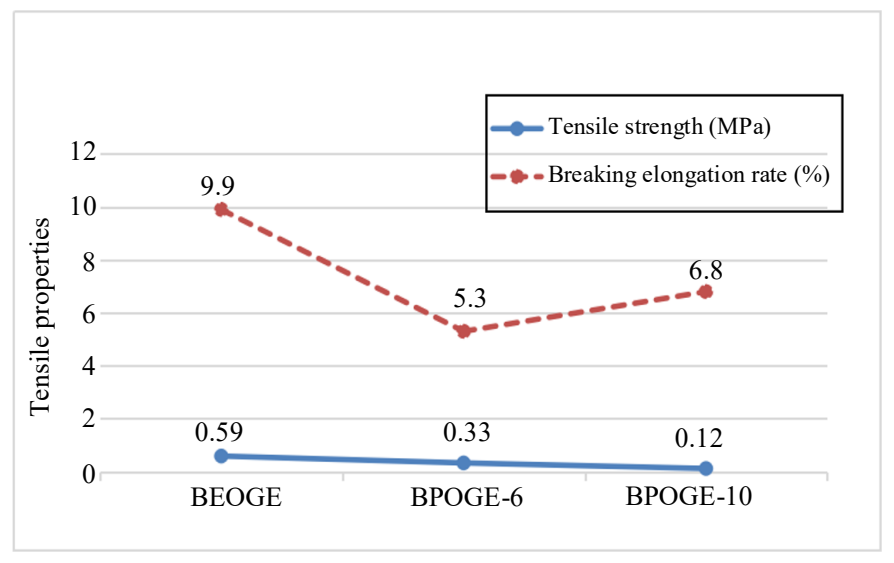

Fig. 5: The effect of different types of a polyether polyol on the tensile properties of cured product

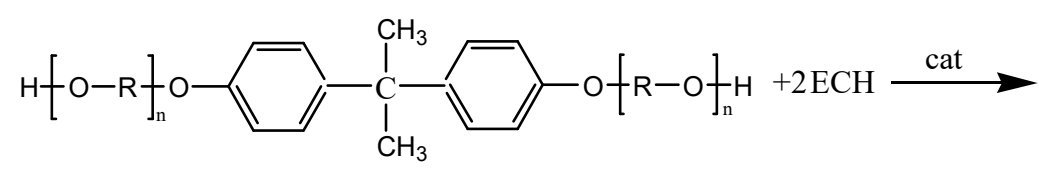<smiles>CCOc1ccc(C(C)(C)c2ccc(O[R](C)OCC(O)C(O)CCl)cc2)cc1</smiles>

Fig. 6: The reaction process of synthesizing chlorohydrin ethers with BEO-6 and epichlorohydrin as raw materials<smiles>CO[R](C)Oc1ccc(C(C)(C)c2ccc(OCC3CO3)cc2)cc1</smiles>

Where, $\mathrm{R}$ and $\mathrm{n}$ are the same as above.

Fig. 7: Reaction formula of hydrophilic epoxy resin formed by reaction of chlorohydrin ether and sodium hydroxide 


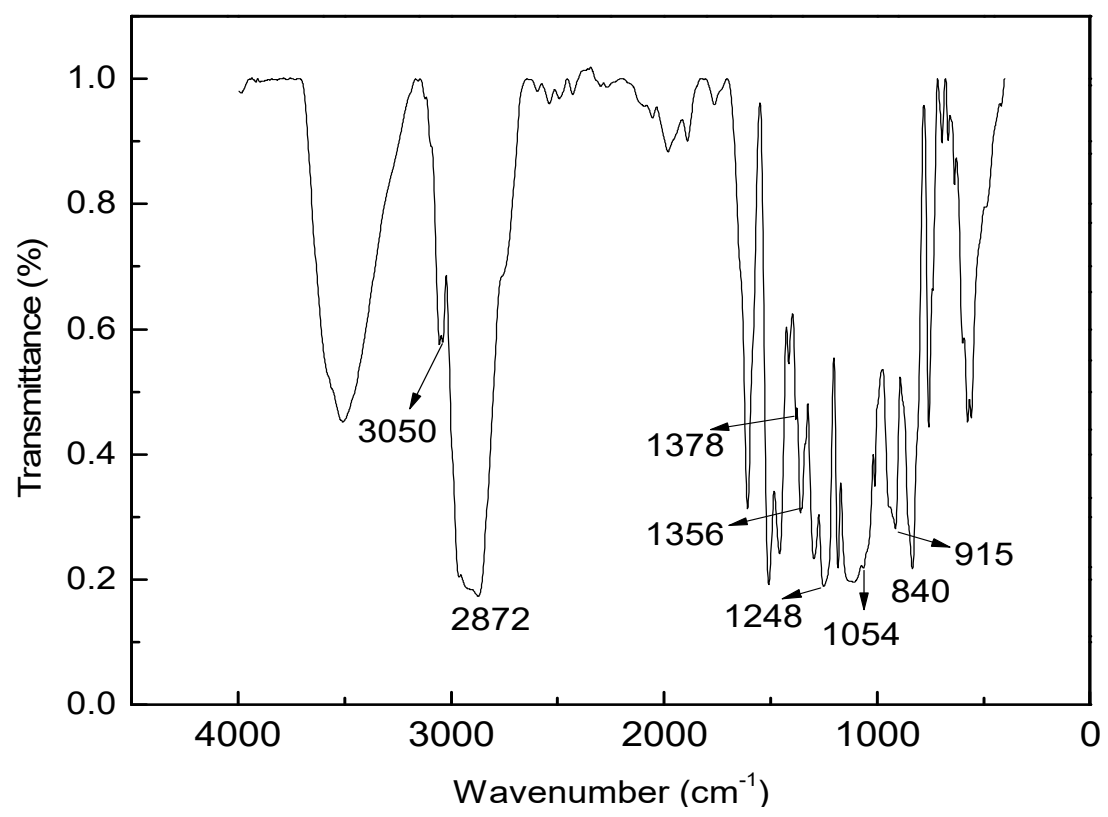

Fig. 8: Infrared spectrum of hydrophilic epoxy resin BEOGE

\section{Infrared Spectroscopy Analysis of Hydrophilic Epoxy Resin}

The infrared spectrum of the hydrophilic epoxy resin BEOGE generated by a polyether polyol BEO-6 and epichlorohydrin under the action of a catalyst is shown in Fig. 8.

It can be seen from Fig. 8 that the characteristic absorption peaks of bending vibration of epoxy groups appear at 915 and $840 \mathrm{~cm}^{-1}$ and the methylene stretching vibration absorption peak of the three-membered ring ether appears at $3050 \mathrm{~cm}^{-1}$. It can be seen that the end epoxy group is formed by the ring-closure reaction of chlorohydrin ether and sodium hydroxide. The peak at $1248 \mathrm{~cm}^{-1}$ in Fig. 8 is attributed to the stretching vibration absorption peak of phenyl ether and the $\mathrm{C}-\mathrm{H}$ stretching vibration absorption peak of the benzene ring at $2872 \mathrm{~cm}^{-1}$. The peak at $1054 \mathrm{~cm}^{-1}$ is the stretching vibration absorption peak of fatty ether. In addition, the characteristic absorption peaks of bending vibration of bis-methyl appear near 1356 and $1378 \mathrm{~cm}^{-1}$. These characteristic absorption peaks indicate that the molecular structure of the hydrophilic epoxy resin BEOGE has the characteristics of a epoxy resin. The molecular structure contains terminal epoxy groups, benzene rings, phenyl ethers, ether groups and dimethyl groups.

According to theoretical analysis, the hydrophilic epoxy resin should contain terminal epoxy groups, benzene rings, phenyl ether, ether groups and dimethyl groups, which indicates that the molecular structure of the hydrophilic epoxy resin BEOGE is in accordance with the experimental design.

\section{Conclusion}

In this study, a kind of hydrophilic epoxy resin is synthesized by the reaction of a polyether polyol with epichlorohydrin in the presence of catalyst. Main conclusions as follows:

(1) Different types of a polyether polyols BEO-6, BPO-6 and BPO-10 are used as raw materials to synthesize the products BEOGE, BPOGE-6 and BPOGE-10 respectively. By analyzing the epoxy value, HLB value, water dispersibility of the synthesized product and the tensile strength and elongation at break of the cured product, it is found that the hydrophilicity, epoxy value, tensile strength and elongation rate of cured product of BEOGE synthesized from BEO are superior to those synthesized from BPO-6 and BPO-10

(2) The HLB value of the product BEOGE synthesized with BEO-6 as raw material is 6.531 , which is between epoxy resin and water-based epoxy resin. It facilitates its adsorption at the oil-water interface and meets the synthesis requirements of hydrophilic epoxy resin

(3) The molecular structure of the product is analyzed by infrared spectroscopy, which is consistent with the synthesis principle of BEOGE, indicating that the synthesis of hydrophilic epoxy resin BEOGE meets the requirements of experimental design

\section{Acknowledgement}

The project is funded by National Natural Science Foundation of China (Grant No. 51779095), Program for 
Science \& Technology Innovation Talents in Universities of Henan Province (Grant No. 20HASTIT013).

\section{Author Contributions}

Jinhua Yi: Research concept and design and writing the article.

Xin Yuan: Data analysis and interpretation and critical revision of the article.

\section{Ethics}

All authors read and approved the final version and are responsible for any ethical issue that may arise after the publication of this manuscript.

\section{References}

Berti, C., Colonna, M., Fiorini, M., Lorenzetti, C., \& Marchese, P. (2004). Chemical modification of terephthalate polyesters by reaction with bis (hydroxyethyl ether) of A. Macromolecular Materials and Engineering, 289(1), 49-55. https://doi.org/10.1002/mame.200300111

Bogdal, D., Gorczyk, J., \& Kwasek, B. (2016). Microwaveassisted synthesis of solid epoxy resins: study of molecular weight by GPC and MALDI-TOF/MS. ACS Sustainable Chemistry \& Engineering, 4(6), 3024-3031. https://doi.org/10.1021/acssuschemeng.5b01786

Essid, S., Hegde, V. J., Mahieu, A., Bizet, L., Leblanc, N., \& Saouab, A. (2021). Comparison of the properties of flax shives based particleboards prepared using binders of bio-based lignin and partially bio-based epoxy resin. International Journal of Adhesion and Adhesives, 102915. https://doi.org/10.1016/j.ijadhadh.2021.102915

Faye, I., Decostanzi, M., Ecochard, Y., \& Caillol, S. (2017). Eugenol bio-based epoxy thermosets: from cloves to applied materials. Green Chemistry, 19(21), 5236-5242. https://doi.org/10.1039/C7GC02322G

Fernández-Álvarez, M., Velasco, F., Torres-Carrasco, M., \& Bautista, A. (2021). Hindering the decrease in wear resistance of UV-exposed epoxy powder coatings by adding nano- $\mathrm{SiO}_{2}$ through ball milling. Wear, 203935. https://doi.org/10.1016/j.wear.2021.203935

Guo, D., Wu, S., Lyu, G., \& Guo, H. (2017). Effect of molecular weight on the pyrolysis characteristics of alkali lignin. Fuel, 193, 45-53. https://doi.org/10.1016/j.fuel.2016.12.042

Huseien, G. F., Sam, A. R. M., Faridmehr, I., \& Baghban, M. H. (2021). Performance of Epoxy Resin Polymer as Self-Healing Cementitious Materials Agent in Mortar. Materials, 14(5), 1255. https://doi.org/10.3390/ma14051255
Janvier, M., Hollande, L., Jaufurally, A. S., Pernes, M., Ménard, R., Grimaldi, M., ... \& Allais, F. (2017). Syringaresinol: a renewable and safer alternative to a for epoxy-amine resins. ChemSusChem, 10(4), 738-746. https://doi.org/10.1002/cssc.201601595

Jdidi, H., Fourati, N., Zerrouki, C., Ibos, L., Fois, M., Guinault, A., ... \& Guermazi, H. (2021). Exploring the optical and dielectric properties of bifunctional and trifunctional epoxy polymers. Polymer, 228, 123882. https://doi.org/10.1016/j.polymer.2021.123882

Kong, M., Liu, C., Tang, B., Xu, W., Huang, Y., \& Li, G. (2019). Improved mechanical and thermal properties of trifunctional epoxy resins through controlling molecular networks by ionic liquids. Industrial \&Engineering Chemistry Research, 58(19), 8080-8089. https://doi.org/10.1021/acs.iecr.9b00547

Kumar, H., \& Swamy, R. P. (2021). Fatigue life prediction of glass fiber reinforced epoxy composites using artificial neural networks. Composites Communications, 100812. https://doi.org/10.1016/j.coco.2021.100812

Lee, W., Wie, J., \& Kim, J. (2021). Enhancement of thermal conductivity of alumina/epoxy composite using poly (glycidyl methacrylate) grafting and crosslinking. Ceramics International, 47(13), 1866218668.https://doi.org/10.1016/j.ceramint.2021.03.198

Li, Z., Ravenni, G., Bi, H., Weinell, C. E., Ulusoy, B., Zhang, Y., \& Dam-Johansen, K. (2021). Effects of biochar nanoparticles on anticorrosive performance of zinc-rich epoxy coatings. Progress in Organic Coatings, 158, 106351. https://doi.org/10.1016/j.porgcoat.2021.106351

Munguia-Lopez, E. M., \& Soto-Valdez, H. (2001). Effect of heat processing and storage time on migration of a (BPA) and A-diglycidyl ether (BADGE) to aqueous food simulant from Mexican can coatings. Journal of agricultural and food chemistry, 49(8), 3666-3671. https://doi.org/10.1021/jf0009044

Papanicolaou, G. C., \& Anastasiou, D. E. (2021). Development of environmentally friendly epoxy and composite adhesives and applications in single and mixed-modulus joints. Journal of Adhesion Science and Technology, 35(11), 1138-1153. https://doi.org/10.1080/01694243.2020.1836787

Parvathy, P. A., \& Sahoo, S. K. (2021). Hydrophobic, moisture resistant and biorenewable paper coating derived from castor oil based epoxy methyl ricinoleate with repulpable potential. Progress in Organic Coatings, 158, 106347. https://doi.org/10.1016/j.porgcoat.2021.106347 
Wang, X., Zhang, X., Caldona, E. B., Leng, W., Street, J., Wang, G., \& Zhang, Z. (2021). Anticorrosive epoxy coatings containing ultrafine bamboo char and zinc particles. Journal of Environmental Chemical Engineering, 9(4), 105707. https://doi.org/10.1016/j.jece.2021.105707
Yu, P., Manalo, A., Ferdous, W., Abousnina, R., Salih, C., Heyer, T., \& Schubel, P. (2021). Investigation on the physical, mechanical and microstructural properties of epoxy polymer matrix with crumb rubber and short fibres for composite railway sleepers. Construction and Building Materials, 295, 123700. https://doi.org/10.1016/j.conbuildmat.2021.123700 